\title{
A study of local turbulence and anisotropy during the afternoon and evening transition with an unmanned aerial system and mesoscale simulation
}

\author{
Astrid Lampert ${ }^{1}$, Falk Pätzold ${ }^{1}$, Maria Antonia Jiménez ${ }^{2}$, Lennart Lobitz ${ }^{1}$, Sabrina Martin ${ }^{3}$, Gerald Lohmann $^{4}$, \\ Guylaine Canut $^{5}$, Dominique Legain ${ }^{5}$, Jens Bange ${ }^{6}$, Dani Martínez-Villagrasa ${ }^{2}$, and Joan Cuxart ${ }^{2}$ \\ ${ }^{1}$ Institute of Flight Guidance, TU Braunschweig, Braunschweig, Germany \\ ${ }^{2}$ Universitat de les Illes Balears, Palma de Mallorca, Spain \\ ${ }^{3}$ Climatology and Environmental Meteorology, Institute of Geoecology, TU Braunschweig, Braunschweig, Germany \\ ${ }^{4}$ Energy Meteorology Group, Institute of Physics, Oldenburg University, Oldenburg, Germany \\ ${ }^{5}$ CNRM-GAME, UMR3589, Météo-France and CNRS, Toulouse, France \\ ${ }^{6}$ Eberhard Karls University Tübingen, Tübingen, Germany
}

Correspondence to: Astrid Lampert (astrid.lampert@tu-braunschweig.de)

Received: 9 January 2016 - Published in Atmos. Chem. Phys. Discuss.: 29 January 2016

Revised: 2 June 2016 - Accepted: 8 June 2016 - Published: 1 July 2016

\begin{abstract}
Observations of turbulence are analysed for the afternoon and evening transition (AET) during the BoundaryLayer Late Afternoon and Sunset Turbulence (BLLAST) experimental field campaign that took place in Lannemezan (foothills of the Pyrenees) in summer 2011. The case of 2 July is further studied because the turbulence properties of the lower atmosphere (up to $300 \mathrm{~m}$ above ground level) were sampled with the Meteorological Mini Aerial Vehicle $\left(\mathrm{M}^{2} \mathrm{AV}\right)$ from turbulently mixed to stably stratified atmospheric conditions. Additionally, data from radiosoundings, $60 \mathrm{~m}$ tower and UHF wind profiler were taken together with the model results from a high-resolution mesoscale simulation of this case. Weak large-scale winds and clear-sky conditions were present on the studied AET case favouring the development of slope winds and mountain-plain circulations. It is found that during the AET the anisotropy of the turbulent eddies increases as the vertical motions are damped due to the stably stratified conditions. This effect is enhanced by the formation of a low-level jet after sunset. Finally, the comparison of the anisotropy ratio computed from the different sources of observations allow us to determine the most relevant scales of the motion during the AET in such a complex terrain region.
\end{abstract}

\section{Introduction}

The afternoon-evening transition (AET) of the atmospheric boundary layer $(\mathrm{ABL})$ involves the processes of converting a convective ABL into a stably stratified nocturnal ABL. The afternoon transition (AT) and evening transition (ET) are defined differently in the literature, depending on, e.g. the observational techniques and available data sets. Some definitions are based on the surface heat flux evolution (Caughey et al., 1979; Grant, 1997; Beare et al., 2006), as in Lothon et al. (2014), who apply the definition by Nadeau et al. (2011) to the BLLAST (Boundary-Layer Late Afternoon and Sunset Turbulence) campaign. The AT begins when the surface heat flux starts to decrease, and afterwards the ET occurs when the surface sensible heat flux becomes negative (close to sunset), with the formation of a temperature inversion above the Earth's surface. This process finishes when a stably stratified boundary layer is well established.

The AET usually includes several consecutive changes of near-surface parameters that have also been used for alternative definitions: a decrease in wind speed (Mahrt, 1981) and temperature is typical, sometimes with a significant change of the wind direction (Stull, 1988), while the mixing ratio within the ABL rapidly increases (Fitzjarrald and Lala, 1989). Besides, the generation of a temperature inversion is responsible for a general drop in horizontal and vertical 
wind variances (Busse and Knupp, 2012) and thermal fluctuations. Consequently, the decay of the turbulence kinetic energy (TKE) occurs in two stages (Nadeau et al., 2011): a slow decay of TKE during the AT followed by a rapid collapse during the ET. The last stage of this evolution is often complemented with a change in turbulence characteristics like its spectral shape or anisotropy (Darbieu et al., 2015). Under unstable stratification and low wind speed conditions, turbulence is mainly generated by convection, and the variance in the vertical is similar to the one in the horizontal wind components, leading to isotropic turbulence and large values of TKE. Along the AET, turbulence anisotropy may arise from the effect of the thermal stratification that inhibits the extent of the vertical motions.

During the AET, spatial inhomogeneities are created, which influence the development of the ABL through the night (Acevedo and Fitzjarrald, 2001; Cuxart et al., 2016). Over complex terrain, temperature gradients at local scales (Conangla and Cuxart, 2006) or larger-scale structures (Bonner, 1968) normally associated with topography are responsible for the generation of a low-level jet (LLJ), first described in Blackadar (1957). This feature is described as a local maximum (Bonner, 1968; Banta, 2008) of wind speed with values $2 \mathrm{~m} \mathrm{~s}^{-1}$ larger than at lower and higher levels (alternatively, an LLJ is also considered if the wind decreases above and below at least $25 \%$ of the maximum, as in Baas et al., 2009). LLJs are frequently reported over land (Lenschow et al., 1988), initiated during the AET and reach near-steadystate conditions at night, when the ABL decouples from the ground as the surface temperature cools down and a temperature inversion layer is formed. Some climatologies report LLJ occurrence between 30 and $60 \%$ of all nights (Song et al., 2005; Baas et al., 2009; Emeis, 2014; Lampert et al., 2015), with the exact percentage depending on the local features and ambient conditions. When an LLJ is present, the wind shear between the surface and the wind maximum is enhanced and the corresponding turbulent mixing (Cuxart and Jiménez, 2007; Kallistratova et al., 2013) decreases the intensity of the surface temperature inversion. Besides, the wind shear associated to the LLJ favours the elongation of the eddies along the main wind direction (Mason and Thomson, 1987; Mauritsen and Svensson, 2007), leading to larger values of anisotropy compared to areas where the LLJ is weaker or non-existent.

The aim of this work is twofold: firstly, to evaluate the changes in the turbulence characteristics during the AET for the lower ABL, with special regard to the isotropy of turbulent eddies, and secondly, to study the influence of a nocturnal LLJ on these turbulence properties. A case from the BLLAST experimental field campaign (Lothon et al., 2014) is taken where clear-sky and weak pressure gradient conditions were present to favour the formation of a mountainplain circulation, as previously reported in Jiménez and Cuxart (2014). An LLJ was generated during that ET, when turbulent measurements in the lower ABL were taken by the Meteorological Mini Aerial Vehicle $\left(\mathrm{M}^{2} \mathrm{AV}\right)$. The analysis is complemented by other sources of observations (standard and frequent radiosoundings, UHF and $60 \mathrm{~m}$ tower) and a high-resolution mesoscale simulation with the MesoNH model (Lafore et al., 1998). A detailed analysis of the increase in anisotropy during the AET for all the IOPs during BLLAST is reported in Canut et al. (2016), but here the case of 2 July 2011 is further studied with the help of $\mathrm{M}^{2} \mathrm{AV}$ observations and mesoscale modelling. The manuscript is organized as follows. Section 2 is devoted to the observations and model set-up. The organization of the flow at lower levels and a description of the turbulent motions, as described in Sects. 3 and 4, evaluates the measured and modelled anisotropy ratio. Finally, discussion of the results and conclusions are shown in Sects. 5 and 6 respectively.

Throughout the article, times are given in UTC, as the study area has approximately the same longitude as Greenwich and therefore the same solar time. The official local time is UTC $+2 \mathrm{~h}$.

\section{Field site, instrumentation and model set-up}

The BLLAST experimental field campaign, conducted in summer 2011 in southern France (Fig. 1a), was dedicated to study the physical processes that take place in the AT (Lothon et al., 2014). Measurements were taken at three different sites spanning a triangle with sides about 3-4 km long, close to Lannemezan, over a plateau at $600 \mathrm{~m}$ above sea level (a.s.l.) approximately $20 \mathrm{~km}$ north of the Pyrenees mountain range. The experimental area was located following the exit of the Aure valley. The Aure valley is a narrow valley, $30 \mathrm{~km}$ long, with the main axis oriented approximately in the north-south direction. Data used here are from the main site (Site 1, asterisk in Fig. 1b) and Site 2 (dot in Fig. 1b), both equipped with various in situ and remote sensing instruments, the main features of which are described below:

- Standard GRAW and MODEM radiosondes were launched from Site 1 at least four times per day at 05:00, 11:00, 17:00 and 23:00 UTC during the intensive operation period (IOP) days. Additional radiosondes were launched at 2030 UTC on 2 July and at 02:00 on 3 July 2011. At Site 2, frequent Väisälä radiosoundings (Legain et al., 2013) were performed every hour from 13:00 to 20:00 UTC. Therefore, differences between simultaneous soundings can be attributed to different launching locations and measurement techniques.

- An ultra-high-frequency (UHF) radar was installed at Site 1 for continuous monitoring of the atmosphere from 200 to $3000 \mathrm{~m}$ above ground level (a.g.l.). The UHF data have a vertical resolution of $75 \mathrm{~m}$ and were averaged over $30 \mathrm{~min}$. Wind and potential temperature reported from the UHF are used in this work. 
(a)

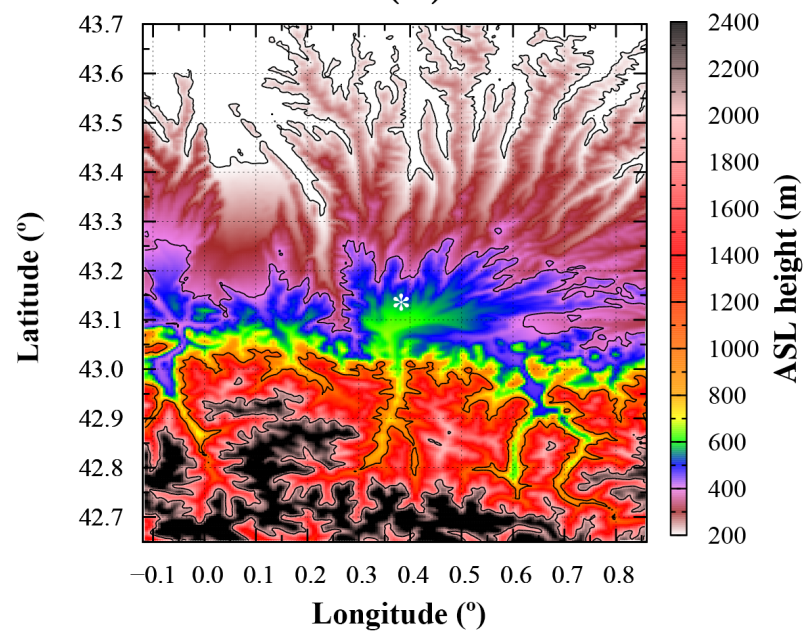

(b)

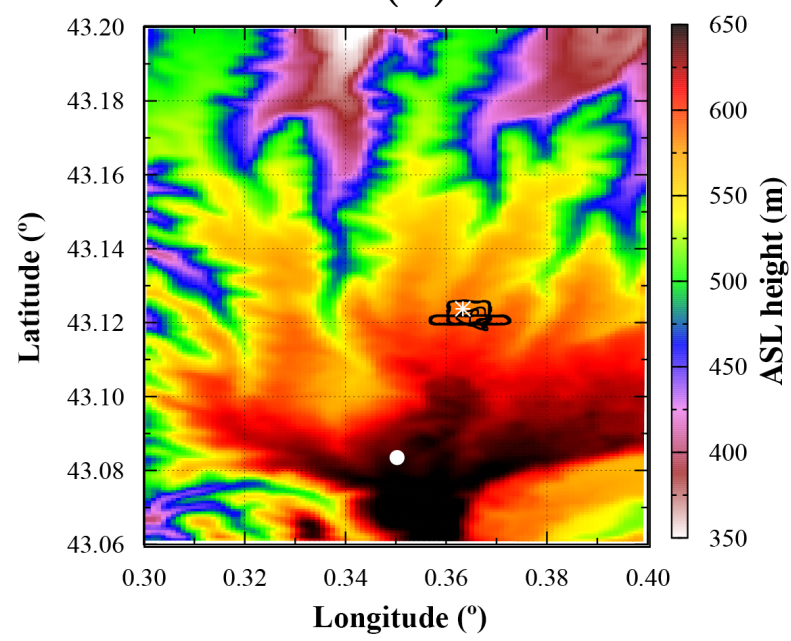

Figure 1. (a) Topography of the inner domain of the mesoscale simulation which covers the Pyrenees (mountains and foothills). The plateau where Lannemezan is placed is coloured in green and the Aure valley is at the south. Topography lines are labelled at 200, 400, 1000 and $2000 \mathrm{~m}$ (above sea level, a.s.1.). (b) Zoom of (a) over the plateau where Lannemezan is placed together with the $\mathrm{M}^{2} \mathrm{AV}$ flight tracks (black lines). The location of Site 1 (60 m tower, UHF radar and GRAW soundings) and Site 2 (frequent radiosoundings, MODEM) are indicated with an asterisk and a dot respectively.

- A $60 \mathrm{~m}$ tower from Centre de Recherches Atmosphériques is permanently installed at Site 1 , providing year-round turbulent measurements at 30,45 and $60 \mathrm{~m}$ a.g.l. Other low-frequency sensors were also installed (Lothon et al., 2014) but they are not used in the current analysis.
Table 1. Takeoff and landing time for each flight of the $\mathrm{M}^{2} \mathrm{AV}$ on 2 July 2011.

\begin{tabular}{c|cc}
\hline Flight & Takeoff [UTC] & Landing [UTC] \\
\hline 1 & $14: 31$ & $15: 14$ \\
2 & $16: 36$ & $16: 59$ \\
3 & $18: 23$ & $19: 04$ \\
4 & $20: 26$ & $21: 10$ \\
\hline
\end{tabular}

\subsection{The Meteorological Mini Aerial Vehicle $\mathrm{M}^{2} \mathrm{AV}$}

Several unmanned aerial vehicles were operated within a radius of $2 \mathrm{~km}$ around Site 1 during the BLLAST campaign. This was particularly the case for the $\mathrm{M}^{2} \mathrm{AV}$ as well, which took four distinct flights during the AET on 2 July 2011. The $\mathrm{M}^{2} \mathrm{AV}$ is an unmanned aerial vehicle with a wing span of $2 \mathrm{~m}$ and a weight of $6 \mathrm{~kg}$. It is started and landed manually and can be fully controlled during the mission by an autopilot system. For this case study, most ascents and descents as well as the main flight, consisting of a race track pattern with straight horizontal legs, were flown with the autopilot. The flight track is shown in Fig. 1b.

The $\mathrm{M}^{2} \mathrm{AV}$ is equipped with a miniaturized turbulence measurement payload comprising a 5-hole probe for deriving the angle of attack and sideslip in the aerodynamic coordinate system. The data can then be converted to the 3-D wind vector in the geodetic coordinate system using precise information on position and attitude of the aircraft obtained by GPS and an inertial measurement unit (IMU). The application of the method for unmanned aircraft is demonstrated by van den Kroonenberg et al. (2008). Further, the payload includes both a slow but accurate (Pt1000) and a fast temperature sensor, as well as a capacitive humidity sensor (Martin et al., 2011). The static air temperature was derived from the Pt1000 thermometer, measuring the stagnation point temperature by correcting the time lag effect and the total temperature effect as described in Stickney et al. (1994) using individual coefficients for the $\mathrm{M}^{2} \mathrm{AV}$. The dry potential temperature was then calculated according to Stull (1988).

The parameters measured by the $\mathrm{M}^{2} \mathrm{AV}$ (profiles of temperature, humidity, wind speed and wind direction, as well as TKE and turbulent fluxes of sensible heat) have been validated extensively against other airborne measurements (Spiess et al., 2007), as well as in situ measurements from a meteorological tower and remote sensing observations (Martin et al., 2011; Cuxart et al., 2012). The system has been deployed for high-resolution atmospheric profiling (Martin et al., 2011; Jonassen et al., 2015) and for deriving turbulent parameters (van den Kroonenberg et al., 2012; Martin et al., 2014; Martin and Bange, 2014) worldwide at various locations.

For the present analysis, the $\mathrm{M}^{2} \mathrm{AV}$ performed four distinct flights starting around 14:30, 16:30, 18:30 and 20:30 UTC. 
Flights lasted approximately 40 min except Flight 2, which was shorter due to a failure of the autopilot around $20 \mathrm{~min}$ after take off. The exact times for take off and landing are given in Table 1. Each flight combined vertical profiles followed by horizontal race track patterns of about $1 \mathrm{~km}$ length oriented in the east-west direction for deriving turbulent parameters. The profiles were performed with an ascent (descent) rate of about 3.5 (8.0) $\mathrm{m} \mathrm{s}^{-1}$. The profiles of wind speed were averaged over intervals of $10 \mathrm{~m}$ altitude for an individual ascent or descent, while wind direction was additionally smoothed using a linear interpolation function. The race track pattern consisted of three legs at 300 and $250 \mathrm{~m}$ a.g.l. and two more legs at $200 \mathrm{~m}$ a.g.l. The same pattern was repeated three times for each flight. During the last flight, these altitudes were reduced by $50 \mathrm{~m}$, corresponding to a lower observed ABL height. Note that the time for one flight leg is only about $45 \mathrm{~s}$ at the aircraft speed of $22 \mathrm{~m} \mathrm{~s}^{-1}$, therefore providing an instantaneous snapshot of the turbulence properties.

Data from the horizontal legs of the race track pattern are used to calculate the turbulent properties at different heights of the lower ABL. Several legs provided time series of the fluctuation part of the wind components with a quasi-steady wave-like structure (wavelength around $2 \mathrm{~km}$ ) of relatively large amplitude compared to the fast fluctuations. This structure had a high impact on the wind variances calculated with a linear detrending. Since the flight legs were not long enough for obtaining statistically relevant information about these longwave features, we decided to remove their impact by employing a high-pass Butterworth filter of third order. After testing different cut-off frequencies, the variances were calculated using the high-pass filter with a frequency of $0.01 \mathrm{~Hz}$.

The dynamic behaviour of the pressure sensors can be different depending on their orientation with respect to the aircraft track, providing discrepancies between the variances estimated for the wind components parallel and perpendicular to the race track. If isotropy is assumed in the horizontal plane, the wind variance parallel to the race track $\sigma_{\mathrm{u}}^{2}$ can be replaced by $\sigma_{\mathrm{v}}^{2}$, according to the meteorological coordinate system. This is not in agreement with the results of Luhar (2010) but is a common approach for airborne data obtained at a high air speed compared to wind speed (Paluch and Baumgardner, 1989; Gultepe and Starr, 1995; Meischner et al., 2001). A convective ABL generates isotropic turbulence, while in a sheared ABL, the eddies are elongated following the direction of the main wind, as described in Mason and Thomson (1987), and therefore they lose isotropy. However, in this case the eddy sizes in the transversal direction have scales of the order of $1 \mathrm{~km}$ (Stull, 1988), which is comparable to the leg length of the $\mathrm{M}^{2} \mathrm{AV}$, thus we may assume that horizontal isotropy applies for the sampled scales. In addition, as the prevailing wind direction was from the north during the day, the horizontal wind component $v$ corresponds to the along-wind data, which has a higher coherence than the crosswind component, e.g. according to Thebaud (2004).
Assuming horizontal isotropy $\left(\sigma_{\mathrm{u}}^{2}=\sigma_{\mathrm{v}}^{2}\right)$, TKE is calculated for each flight leg as (Stull, 1988)

$\mathrm{TKE}=\frac{1}{2}\left(\sigma_{\mathrm{u}}^{2}+\sigma_{\mathrm{v}}^{2}+\sigma_{\mathrm{w}}^{2}\right)=\sigma_{\mathrm{v}}^{2}+\frac{1}{2} \sigma_{\mathrm{w}}^{2}$

For investigating the turbulence anisotropy, the anisotropy ratio is defined in this study as the ratio of horizontal-tovertical wind variances (Darbieu et al., 2015).

$A=\frac{\sigma_{\mathrm{u}}^{2}+\sigma_{\mathrm{v}}^{2}}{2 \sigma_{\mathrm{w}}^{2}}=\frac{\sigma_{\mathrm{v}}^{2}}{\sigma_{\mathrm{w}}^{2}}$.

where $\sigma_{\mathrm{u}}^{2}=\sigma_{\mathrm{v}}^{2}$ is also assumed when calculating this parameter with airborne data. Equation (2) implies that isotropic turbulence is characterized with $A=1$; that values lower than 1 correspond to daytime convection with a large vertical turbulence component; values exceeding 1 are caused by a dominating turbulence component in the horizontal direction induced by wind shear or by a decrease of the vertical variance under stably stratified conditions. Despite the fact that here we use a different definition of the anisotropy ratio compared to other studies (e.g. Mauritsen and Svensson, 2007; Canut et al., 2016), all of them can be easily related.

\subsection{Model set-up}

The mesoscale model MesoNH (Lafore et al., 1998) was run in a similar manner to previous studies, particularly in the Garonne river basin (see Jiménez and Cuxart, 2014, and the references therein). Two nested domains were used. The outer one, at $2 \mathrm{~km} \times 2 \mathrm{~km}$ resolution (domain size of $50 \mathrm{~km} \times 480 \mathrm{~km}$ ), covered the Garonne river and the inner one, at $400 \mathrm{~m} \times 400 \mathrm{~m}$ resolution (domain size of $80 \mathrm{~km} \times 120 \mathrm{~km}$ ), was centred in Lannemezan (see Fig. 1a). The vertical resolution is fine close to the surface $(3 \mathrm{~m})$ to properly represent the physical processes that take place at lower levels, and coarser above the surface. The initial and lateral boundary conditions are taken from the European Centre for Medium-Range Weather Forecasts (ECMWF) every $6 \mathrm{~h}$.

For the case study, the simulation start time was set to 00:00 UTC on 29 June 2011 so that rain observed during 30 June could be included, with the aim that soil moisture in the model would be more similar to the observations. The simulation end time was set to 12:00 UTC on 3 July 2011. For the case study, attention is focused on describing the AET of 2 July 2011 (from 15:00 to 00:00 UTC).

\section{Flow at lower levels during the AET}

The synoptic conditions during 2 July 2011 include a weak anticyclone $(1025 \mathrm{hPa})$ over Britain and Ireland, with lower values of the pressure field at the mean sea level on the 

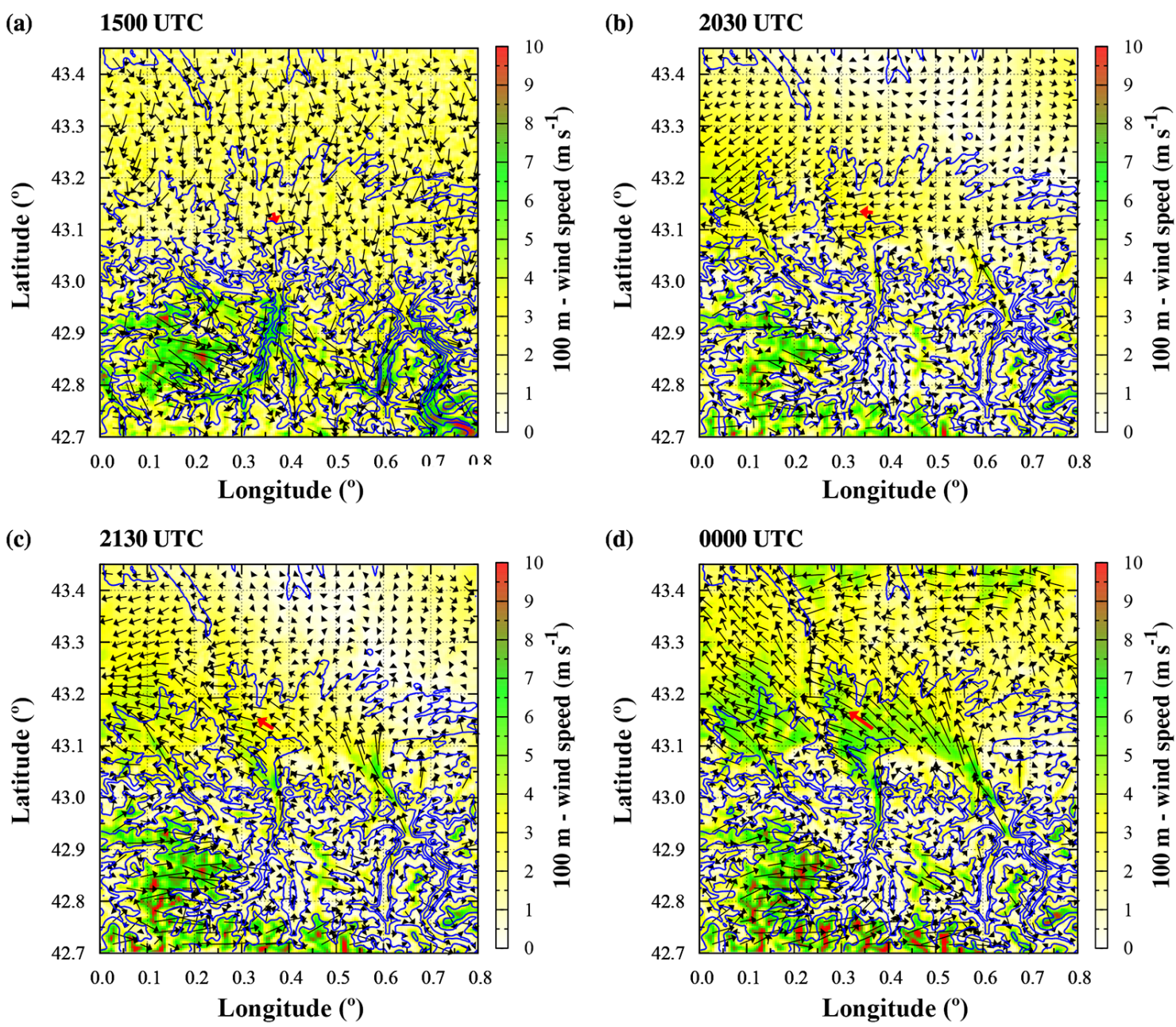

Figure 2. Modelled $100 \mathrm{~m}$ a.g.l. wind vectors together with wind speed (in colours) and the topography lines (in blue) at different instants (a) 15:00, (b) 20:30, (c) 21:30, (d) 00:00 UTC. The $60 \mathrm{~m}$ wind vector observed by the tower is indicated with a red arrow.

western Mediterranean (1012 hPa), resulting in a weak northeasterly to east-north-easterly flow over southern France at low levels. This synoptic-scale flow coexisted with the mountain-plain system that generated northerly flows in the daytime over the foothills of the Pyrenees (Fig. 2a). Additionally, the Aure valley, just south of Lannemezan, had a well developed up-valley wind system. At 20:30 UTC, the wind in the plain blew from east-north-east (also over Lannemezan, Fig. 2b), whereas the mountain valleys were generating down-valley flows that still did not reach the foothills where Lannemezan is located. Just $1 \mathrm{~h}$ later (Fig. 2c), the site was located in an area where the mountain-to-plain wind merged with the more general easterly wind, resulting in a local wind maximum over Lannemezan (an LLJ, as it will be described later), a structure that still stayed there and was even reinforced at 00:00 UTC (Fig. 2d). The model reproduces the observed intensity and direction of the wind in Lannemezan (red arrow in Fig. 2) very well for all the inspected instants.
Looking at the temporal series in Fig. 3 from $\mathrm{M}^{2} \mathrm{AV}, 60 \mathrm{~m}$ tower and mesoscale simulation, the wind speed at $60 \mathrm{~m}$ a.g.l. decreases during the AET (with a higher rate for airborne observations) and increases again substantially after sunset, as wind turns from north to north-east direction, a behaviour that the model and the $\mathrm{M}^{2} \mathrm{AV}$ observations successfully capture. Besides, the three sources are reproducing a similar temporal evolution of temperature, being the model $1 \mathrm{~K}$ warmer and $1 \mathrm{~K}$ colder than the observations during day and night respectively. Although these biases are not large, similar values are found for other studies and they can be attributed to an enhanced mixing of the model at lower levels (Conangla and Cuxart, 2006) or to a misrepresentation of the surface heterogeneities (Cuxart et al., 2016).

To inspect the vertical characteristics of the LLJ, the profiles observed by the UHF profiler and those extracted from the model outputs are shown as Hövmoller plots $(z, t)$ in Fig. 4. Besides, in Fig. 5 the observed vertical profiles 
(a)

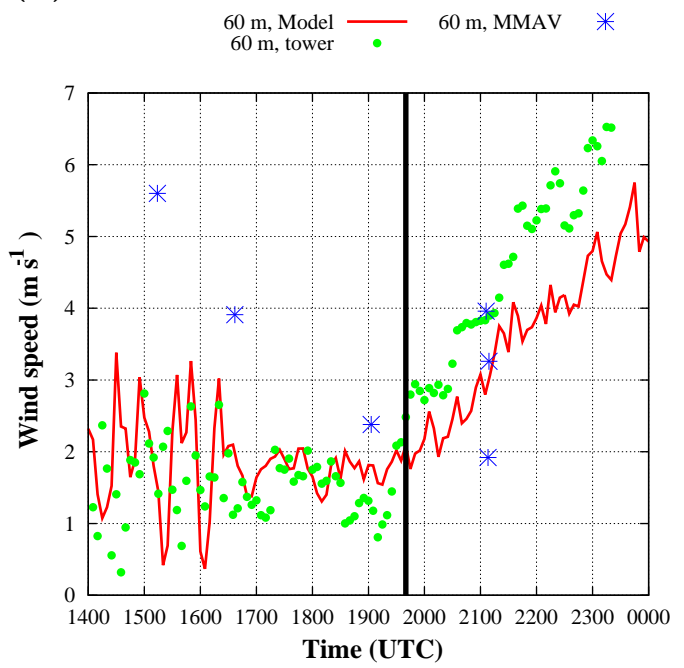

(c)

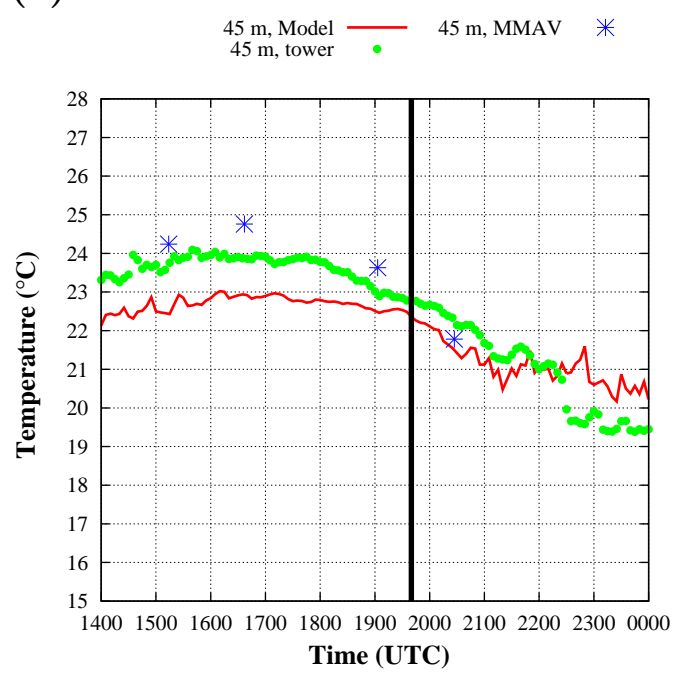

(b)

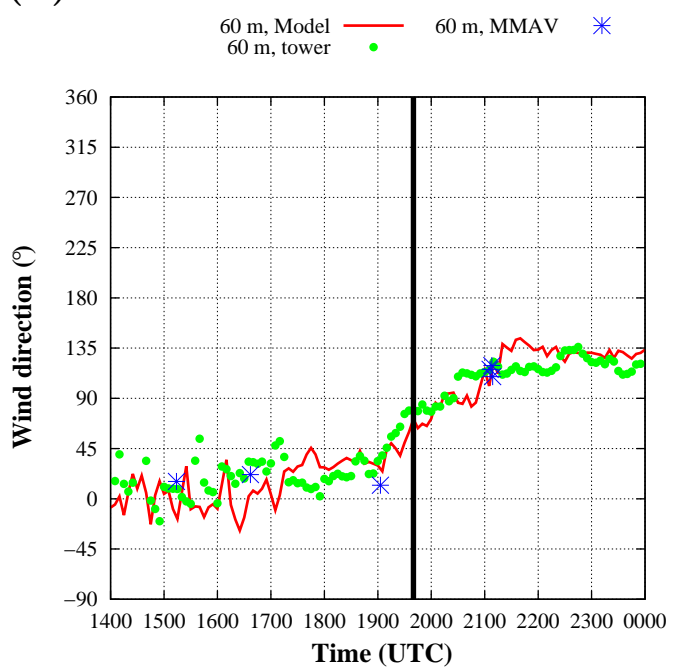

(d)

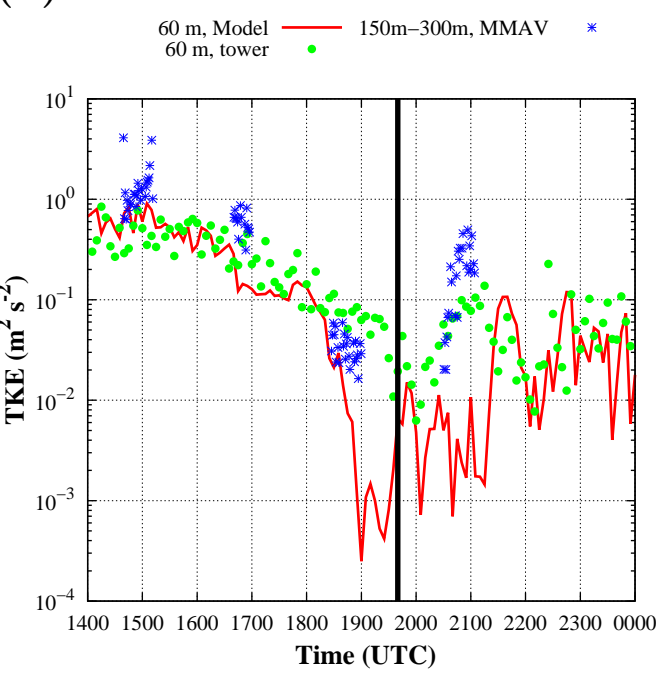

Figure 3. Modelled and observed time series for (a) wind speed (in $\mathrm{m} \mathrm{s}^{-1}$ ), (b) wind direction (in ${ }^{\circ}$ ), (c) temperature (in ${ }^{\circ} \mathrm{C}$ ) and (d) TKE (in $\mathrm{m}^{2} \mathrm{~s}^{-2}$ ) from 14:00 UTC until midnight on 2 July 2011. Tower observations are in green circles, model results in red lines and $\mathrm{M}^{2} \mathrm{AV}$ data in blue asterisks. The temporal evolution of wind and temperature data from $\mathrm{M}^{2} \mathrm{AV}$ is constructed with the values of the vertical profiles taken at the corresponding height of the tower measurements. For TKE, all the $\mathrm{M}^{2} \mathrm{AV}$ legs where TKE is derived, at 150, 200, 250 and $300 \mathrm{~m}$ a.g.l., are included in the plot. The time of sunset is represented by a black vertical line.

$\left(\mathrm{M}^{2} \mathrm{AV}\right.$, UHF, soundings and $60 \mathrm{~m}$ tower) at different instants are compared to those obtained from the model.

It is found that the observed and modelled wind direction are in good agreement with each other. Figure 4a shows that the UHF wind veers from north-east to south-east between 20:00 and 21:00 UTC above $200 \mathrm{~m}$ a.g.l. and continues in that direction over the following hours. The model has a similar behaviour at those heights (Fig. 4c) and indicates that, at lower levels, the south-easterly flow arrives earlier constricted to the first tens of metres AGL (as further confirmed with tower observations, Fig. 3b). The TKE in the model decreases during the AET with a minimum close to sunset at about $200 \mathrm{~m}$ a.g.l. and increases again when the LLJ is present due to its shear. It must be mentioned here that the values of the wind speed as provided by the UHF profiler are always significantly overestimated with respect to the soundings (Fig. 5); instead the wind directions derived from both soundings and wind profiler are in very good agreement. Therefore, when making our assessment of other data and of the model, we will not give too much weight to the values of the UHF profiler for this particular case study. At 19:00 UTC, before sunset, the thermal stratification is already stable at the site, with very weak winds from the northeast quadrant (Fig. 5c). Profiles in Fig. 4 indicate that, at 
(a)

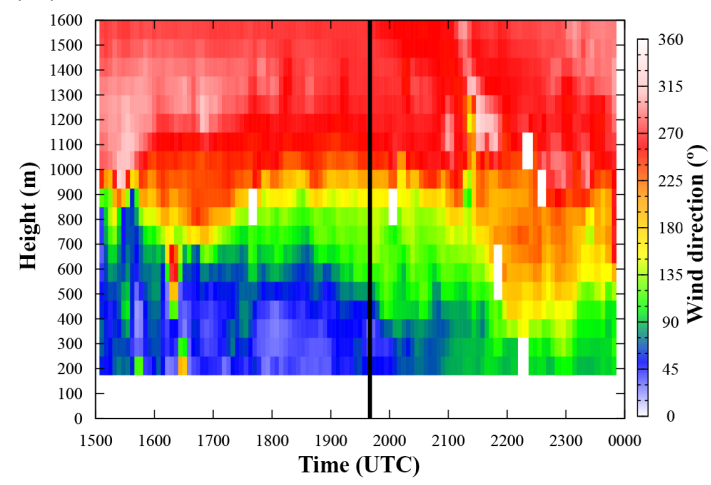

(c)

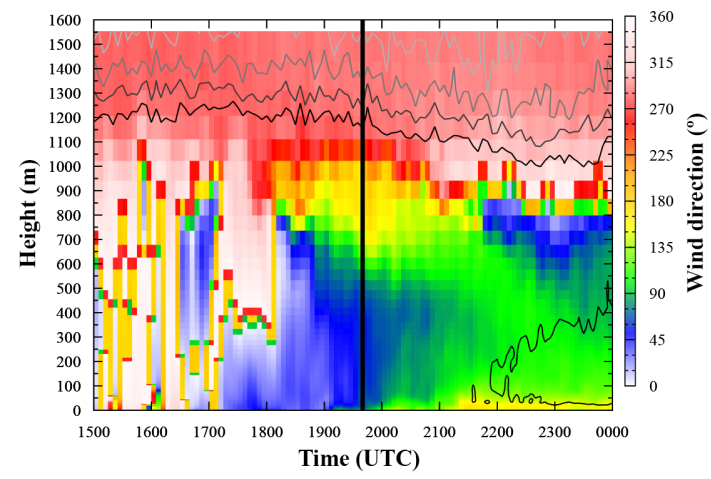

(b)

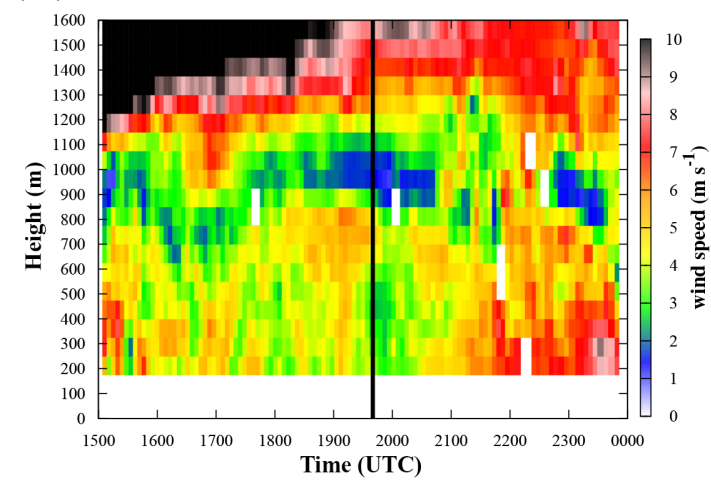

(d)

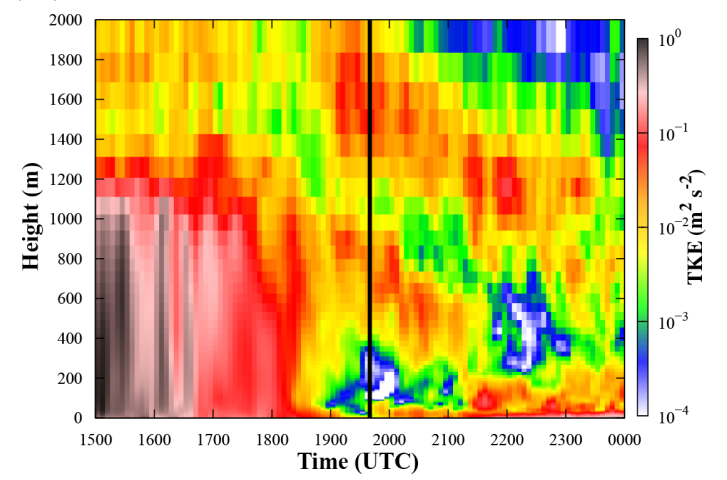

Figure 4. Temporal evolution of the vertical profiles for (a) UHF wind direction (in ${ }^{\circ}$ ), (b) UHF wind speed (in $\mathrm{m} \mathrm{s}^{-1}$ ), (c) MesoNH wind direction (in colours) and wind speed (in lines, for values $\geq 4 \mathrm{~m} \mathrm{~s}^{-1}$, contour interval $=2 \mathrm{~m} \mathrm{~s}^{-1}$ ) and (d) MesoNH TKE (in $\mathrm{m}^{2} \mathrm{~s}^{-2}$ ). The time of sunset is represented by a black vertical line.

20:00 UTC, already after sunset, there is a progressive formation of a south-easterly jet below $100 \mathrm{~m}$ a.g.l., which is clearly developed at 23:00 UTC, detected by the tower measurements below $60 \mathrm{~m}$ and, according to the model, extending up to almost $300 \mathrm{~m}$ a.g.l. with wind speed around $5 \mathrm{~m} \mathrm{~s}^{-1}$. The reported LLJ has similar features as those described in Baas et al. (2009).

$\mathrm{M}^{2} \mathrm{AV}$ profiles (Fig. 5) show a general good agreement with the description just given using model and UHF profiler, indicating the increase in wind speed after sunset and the change of the wind direction. The aeroplane is also able to successfully capture the transition from thermally unstable to stable conditions as shown in the potential temperature profiles (Fig. 5).

It seems therefore clear that the $\mathrm{M}^{2} \mathrm{AV}$ flight just after sunset was able to capture the transition from a very weak wind regime to the establishment of a terrain-induced LLJ that was sustained for several hours (the simulation ends at 12:00 UTC of the next day). Since flight legs were made to estimate turbulence intensities at heights that are probably located above and below the LLJ wind maximum, it is possible that we can infer some characteristics of the turbulence related to this structure using the last flight. Besides, knowing that an LLJ was present in the area sustainedly after sunset provides clues for the interpretation of the increase of anisotropy that will be described in the next section.

During the last flight (about 21:00 UTC) ambient conditions were favourable to develop gravity waves in the ABL, especially at lower levels. Results from Román-Cascón et al. (2015) clearly show the presence of gravity waves close to the surface up to about $100 \mathrm{~m}$ a.g.l. but not at higher levels (where the $\mathrm{M}^{2} \mathrm{AV}$ sampled). The model results are not able to capture these waves since they are too attached to the ground.

\section{Turbulence and anisotropy during the AET}

Observations of the TKE ( 5 min averages from the tower and observations obtained with the $\mathrm{M}^{2} \mathrm{AV}$ ) and model results are similar during the AET, with a sustained decrease in turbulence, and very small values at sunset (Fig. 3d). Once the turbulence collapses around sunset the observed values are very small in the whole column (tower and $\mathrm{M}^{2} \mathrm{AV}$ reported TKE of around $0.05 \mathrm{~m}^{2} \mathrm{~s}^{-2}$, Fig. 6). As seen in this figure, the model produces even smaller TKE values throughout the vertical column, with a local minimum between 75 and 
(a)
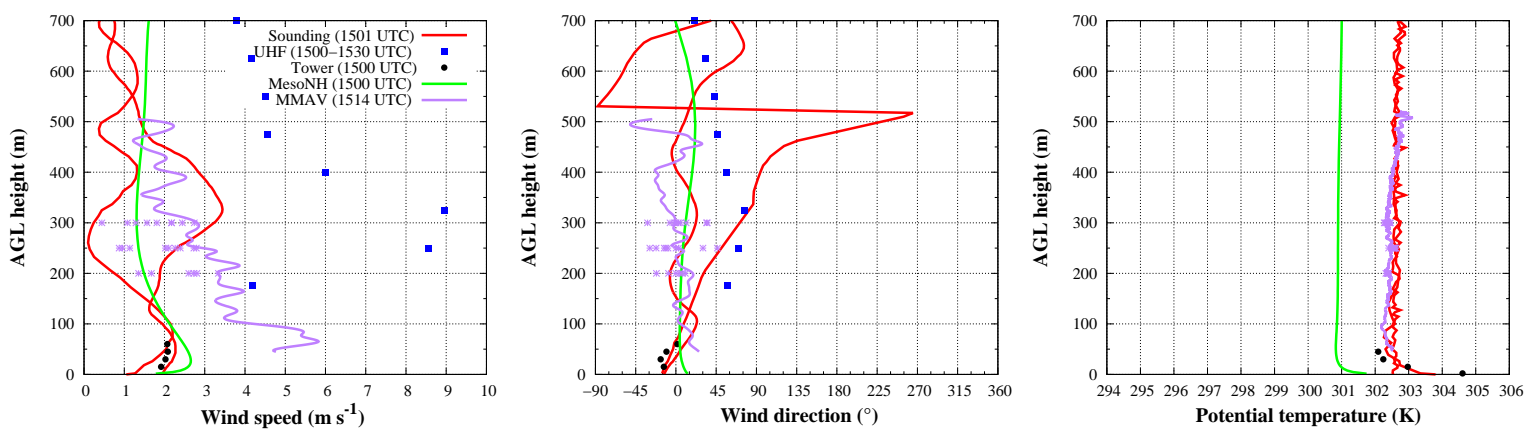

(b)
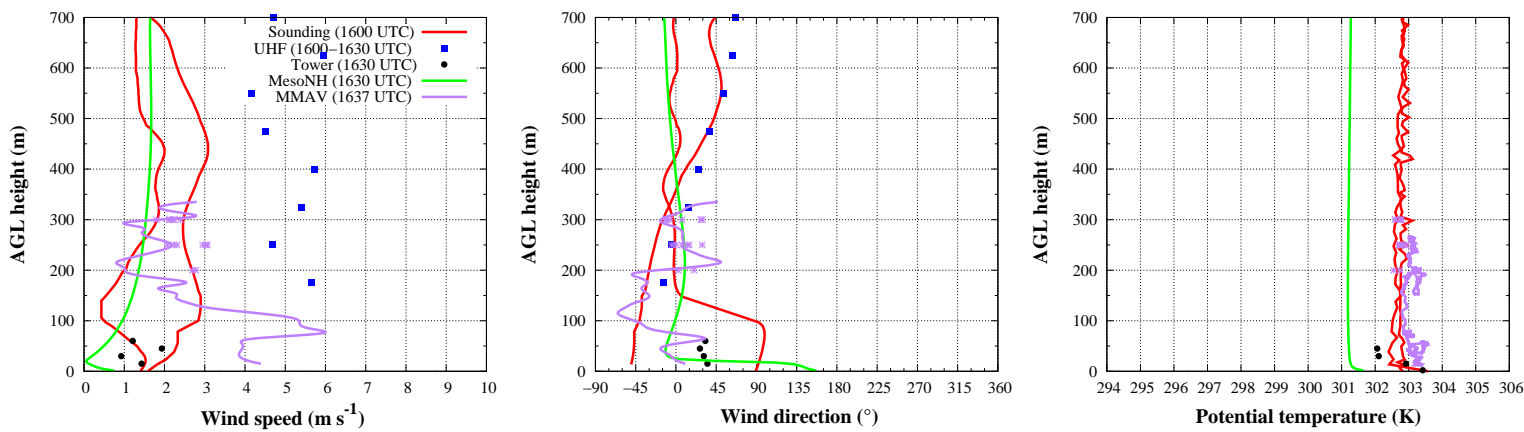

(c)
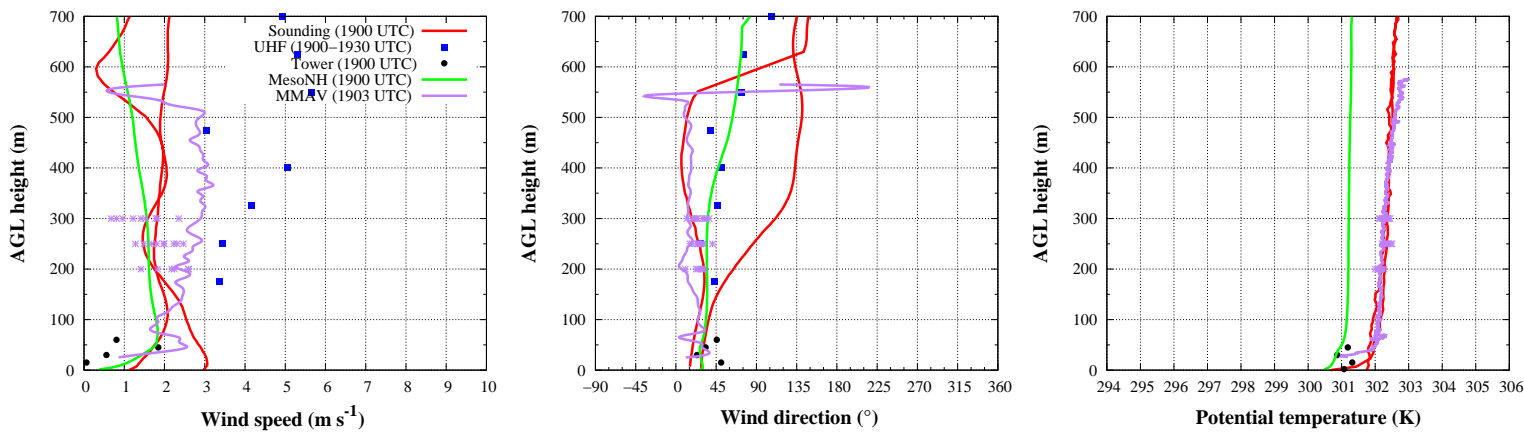

(d)
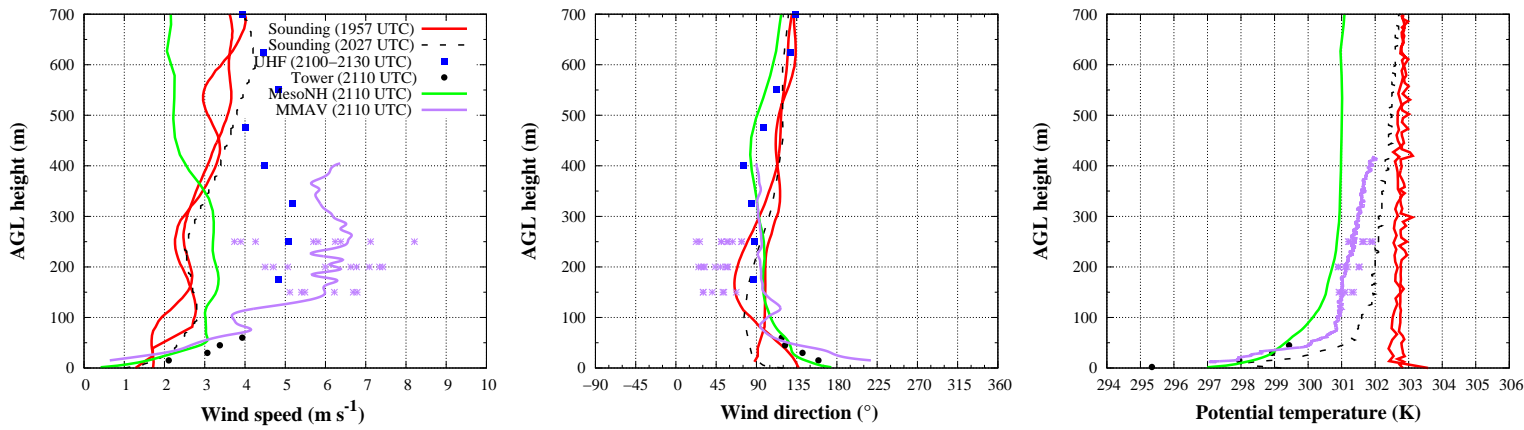

Figure 5. Vertical profiles of the wind speed (in $\mathrm{m} \mathrm{s}^{-1}$ ) on the left, wind direction (in ${ }^{\circ}$ ) in the centre and potential temperature (in $\mathrm{K}$ ) on the right, obtained from $\mathrm{M}^{2} \mathrm{AV}$ (in violet) for the four flights of 2 July 2011: (a) 15:00, (b) 16:30, (c) 19:00 and (d) 21:10 UTC. Purple dots correspond to mean values for each horizontal leg. $\mathrm{M}^{2} \mathrm{AV}$ data are compared against instantaneous observations from UHF (blue squares), $60 \mathrm{~m}$ tower (black dots), and frequent (red) and standard soundings (black), together with mesoscale simulation results (green). The legend indicates the corresponding times to each data source. 


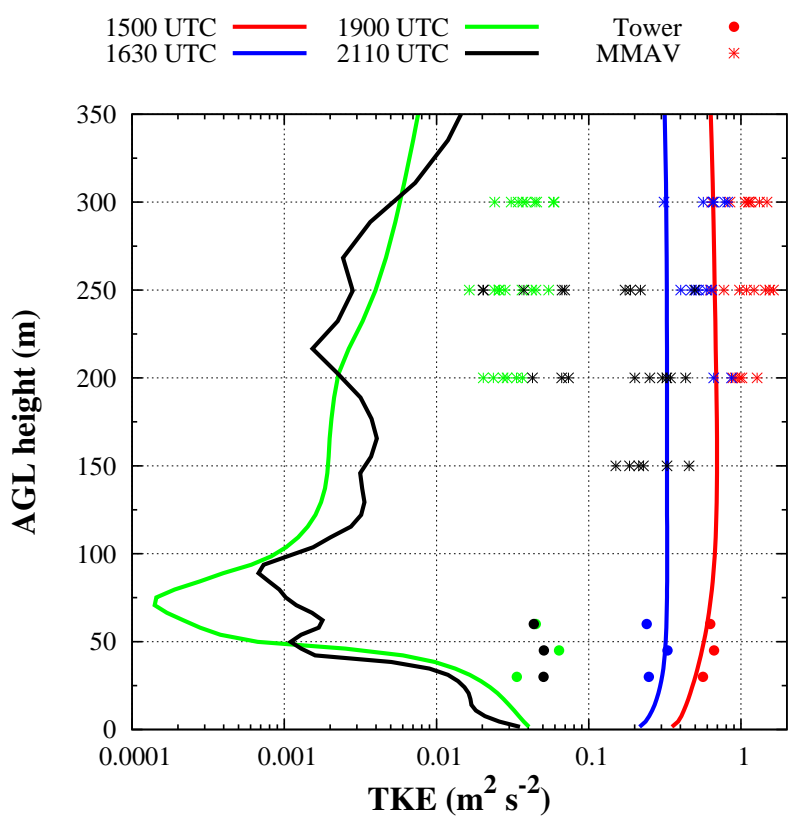

Figure 6. Vertical profiles of the simulated TKE (in lines) at different instants during the $\mathrm{M}^{2} \mathrm{AV}$ flights (see legend). $60 \mathrm{~m}$ tower (in dots) and $\mathrm{M}^{2} \mathrm{AV}$ (in asterisk) observations are also included. Note the logarithmic scale on the $x$ axis. For $\mathrm{M}^{2} \mathrm{AV}, \sigma_{\mathrm{u}}^{2}=\sigma_{\mathrm{v}}^{2}$ is assumed.

$125 \mathrm{~m}$ a.g.l. Simulated results are closer to the observations at lower levels (as those observed by the $60 \mathrm{~m}$ tower) but clearly underestimate the results provided by the $\mathrm{M}^{2} \mathrm{AV}$ at higher elevations. Modelled LLJs usually underestimate the intensity of turbulent mixing compared to observations (Conangla and Cuxart, 2006). Nonetheless, in this case, the local elevated turbulence usually associated to the LLJ wind maximum seems to be reproduced by the mesoscale simulation, as shown by a sustained TKE maximum near $400 \mathrm{~m}$ a.g.l. between sunset and 21:00 UTC (yellow and red colour, Fig. 4d).

The anisotropy ratio for the afternoon and evening transition in this case study can be computed from the numerical model, $\mathrm{M}^{2} \mathrm{AV}$ and the sonic anemometers in the $60 \mathrm{~m}$ tower (Fig. 7). Each source samples different characteristic scales and therefore provides information about the anisotropy at different ranges of the TKE spectrum.

For the model, the columns of a box of $10 \mathrm{~km}$ side centred at Lannemezan are extracted using the smallest domain that has a horizontal resolution of $400 \mathrm{~m}$. The mean values of the horizontal and vertical wind speeds are computed from the $25 \times 25$ columns, and the corresponding standard deviations are computed to obtain the anisotropy ratio. This is the anisotropy corresponding approximately to scales between 1 and $5 \mathrm{~km}$ as created by the model. Afternoon values are slightly below 1 , since in summer prevailing dry-sheared convection typically has a turbulence spectrum with an inertial subrange (IS) starting at scales close to $1 \mathrm{~km}$. As sunset approaches and convection weakens, anisotropy increases

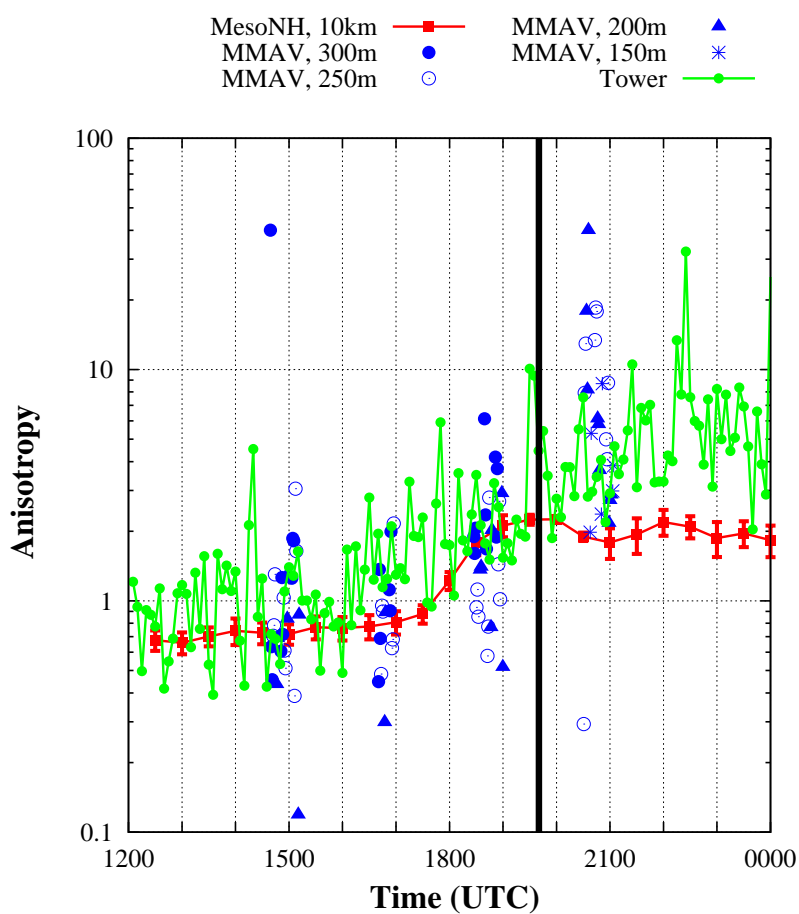

Figure 7. Time series of the anisotropy computed from different sources: (1) $\mathrm{M}^{2} \mathrm{AV}$ flight observations at 150, 200, 250 and $300 \mathrm{ma.g} .1$. during the four flights, each symbol representing a particular height (in blue); (2) tower measurements at $60 \mathrm{~m}$ a.g.l. every 5 min covering the afternoon-evening transition (in green); (3) model results averaged between 150 and $300 \mathrm{~m}$ a.g.l. to be close to the altitudes of the $\mathrm{M}^{2} \mathrm{AV}$ observations considering a spatial area of $10 \mathrm{~km} \times 10 \mathrm{~km}$ centred at Lannemezan (in red). The time of sunset is represented by a black vertical line. Note the logarithmic scale on the $y$ axis. For $\mathrm{M}^{2} \mathrm{AV}, \sigma_{\mathrm{u}}^{2}=\sigma_{\mathrm{v}}^{2}$ is assumed.

because the beginning of the IS shifts to the right. After sunset, the eddies have relatively shallow dimensions and are elongated along the main wind direction (as described in $\mathrm{Ma}-$ son and Thomson, 1987), showing large values of anisotropy at these scales. Anisotropy in the model is at maximum close to the ground and decreases with height (not shown).

The $\mathrm{M}^{2} \mathrm{AV}$ flew legs of $1 \mathrm{~km}$ length and resolves eddies down to sizes of typically a few metres (Martin et al., 2014). In the daytime the range of sampled eddies is almost all in the IS, and the anisotropy ratio has values close to 1 . As sunset approaches and at night, the size of the largest eddies decreases and the aeroplane samples eddies larger than those in the IS, generating larger values of the anisotropy ratio. Statistical values over $5 \mathrm{~min}$ from a sonic anemometer at $60 \mathrm{~m}$ a.g.l. are similar to those from the $\mathrm{M}^{2} \mathrm{AV}$ (close to 10) in this case, typically representing scales of a few hundred metres (assuming a mean wind speed of $5 \mathrm{~m} \mathrm{~s}^{-1}$ ) to dissipation.

In the daytime the values of anisotropy provided by the different sources are very similar and close to 1 , as expected with a dry-sheared convective boundary layer (Fig. 7). Dur- 
(a)

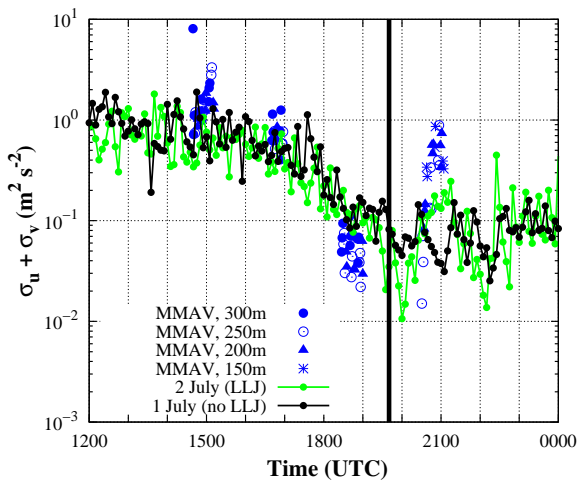

(b)

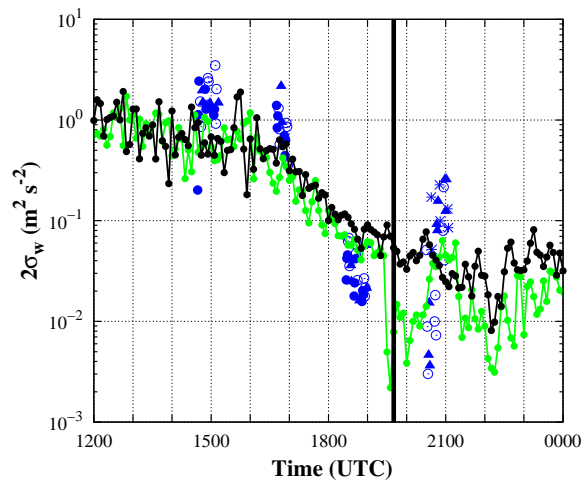

Figure 8. The same as Fig. 7 but for the (a) horizontal $\sigma_{\mathrm{u}}+\sigma_{\mathrm{v}}$ and (b) vertical $2 \sigma_{\mathrm{w}}$ variances computed from the tower observations at 60 m a.g.l. during 1 July 2011 (IOP 9, without an LLJ, black line) and 2 July 2011 (IOP10, with an LLJ, green line), together with those derived from $\mathrm{M}^{2} \mathrm{AV}$ observations. For $\mathrm{M}^{2} \mathrm{AV}$ data, $\sigma_{\mathrm{u}}^{2}=\sigma_{\mathrm{v}}^{2}$ is assumed.

ing the evening transition, the anisotropy ratio is larger (by a factor of 2 to 5), likely because the contribution of convection weakens significantly and the eddies become progressively shallower and more elongated. At night the values of the anisotropy ratio differ depending on the scale and source of the data. At the height of the LLJ, the model produces the same values of anisotropy as during the transition, not significantly influenced by the effects of thermal stratification at those levels and the elongation of shear-driven eddies at those scales. Instead, the $\mathrm{M}^{2} \mathrm{AV}$ and the tower, which measure at smaller scales, provide much higher values of the anisotropy ratio, indicating that thermal stratification and wind shear generated by the LLJ play a more important role at these scales, moving the upper limit of the IS to very small eddies.

\section{Discussion}

The TKE values observed with the $\mathrm{M}^{2} \mathrm{AV}$ are compatible with other TKE values obtained on that particular day with ground-based, balloon and airborne observations (Canut et al., 2016). The time evolution of the TKE studied in the present case can be compared to the results obtained by Darbieu et al. (2015), who analysed the turbulence decay between 12:00 and 20:00 UTC for a similar day of the BLLAST campaign (20 June 2011, IOP 3) using observations and a large eddy simulation (LES). Observed TKE during Flights 1 and 2 are of the same magnitude than those values obtained in Darbieu et al. (2015) between 15:00 and 17:00 UTC (see their Fig. 7). Two hours later, Flight 3 exhibits much lower values than in their study, suggesting that turbulence collapses faster and deeper in our case. Interestingly, the TKE produced by the numerical simulations is lower than the observations for both cases, despite the differences in the study cases and the numerical tools used. After sunset, Flight 4 observes a TKE increment with the arrival of the LLJ, with val- ues between 0.02 and $0.6 \mathrm{~m}^{2} \mathrm{~s}^{-2}$. In the summary of Banta et al. (2006), TKE values around $0.1 \mathrm{~m}^{2} \mathrm{~s}^{-2}$ are reported for LLJs with a similar maximum wind speed around $5 \mathrm{~m} \mathrm{~s}^{-1}$, which is in the same order of magnitude as the observations presented here. However, the direct comparison of absolute TKE values with other values in the literature is often difficult due to the non-unique definition of TKE and data treatment, e.g. over what time the data were averaged, a high-pass filtering technique was applied or a linear trend removal carried out for determining the wind speed variances (cf. Banta et al., 2003).

The change of TKE with altitude does not provide a clear tendency (Fig. 6). According to Banta (2008), a decrease in TKE with altitude is expected for an ABL where turbulence is created at the surface by thermal heating and then transported upwards. In contrast, when turbulence is induced by wind shear aloft, an increase in TKE with altitude is predicted using the theory by Banta (2008) and produced by LES modelling (Nakanishi et al., 2014). In Fig. 6, a large scatter of TKE values can be seen for $\mathrm{M}^{2} \mathrm{AV}$. This indicates that the individual flight legs for deriving turbulence properties were too short and the terrain was too inhomogeneous (Cuxart et al., 2016) to derive values which are statistically representative of the area (Lenschow et al., 1994).

The evolution of turbulence anisotropy, with larger values of the vertical wind variance during the afternoon and of the horizontal variances after sunset, is in accordance with other observations during the BLLAST campaign (Canut et al., 2016). Similarly, the numerical simulations of Darbieu et al. (2015) give a sustained anisotropy ratio around 1 at $z=0.2 z_{i}$ ( $z_{i}$ is the ABL height) until 17:30 UTC, and a rapid increment up to 2.5 after $1 \mathrm{~h}$. These results are in accordance with our observations from Flights 1, 2 and 3 of the $\mathrm{M}^{2} \mathrm{AV}$, since the first two flights exhibit similar anisotropy results while the third one doubles its value (Fig. 7). In addition, observations from Flight 4 suggest that the abrupt increment of 
the anisotropy ratio during the late afternoon, when the surface buoyancy flux reduces to zero (Darbieu et al., 2015), is enhanced after sunset.

In order to evaluate the impact of the LLJ on the turbulence anisotropy, this parameter is evaluated during IOP 9 (1 July) with data from the $60 \mathrm{~m}$ tower and compared against our case study (2 July 2011, IOP 10). Similarly to IOP 10, in IOP 9 large-scale winds were weak, allowing the development of a mountain-plain circulation but without the arrival of an LLJ (Lothon et al., 2014). For both IOPs, the anisotropy ratio at $60 \mathrm{~m}$ a.g.l. increases along the AET, but after sunset it becomes larger for IOP 10 (not shown). Figure 8 shows the temporal evolution of the horizontal and vertical wind variances for both cases separately. The results from $\mathrm{M}^{2} \mathrm{AV}$ are also depicted for reference. During the day, all variances have similar values, remaining steady until 16:00 UTC and decreasing afterwards, as sunset approaches. During this stage, the resulting anisotropy ratio is 1 for both cases. Close to the sunset time, the vertical wind variance decreases at a higher rate and thus the anisotropy ratio increases, as in Kallistratova et al. (2013). After sunset, the drop in $\sigma_{\mathrm{w}}$ is more significant for the IOP 10, coinciding with the arrival of an LLJ at the area. These results are in agreement with previous observations from Prabha et al. (2008) and Banta (2008). The wind shear generated by the presence of the LLJ and the stably stratified conditions at lower levels (at $60 \mathrm{~m}$ a.g.l., see Fig. 4) might be responsible for the drop in $\sigma_{\mathrm{w}}$ after sunrise, where the vertical motions are more damped than if an LLJ is not present.

\section{Conclusions}

This work focuses on the time evolution of turbulence properties at the lower ABL during the afternoon and evening transition (AET) for a case study of the BLLAST experimental field campaign in southern France. The analysis has been carried out through airborne, tower, radiosonde and remote sensing (UHF wind profiler) observations. Besides, results from a high-resolution mesoscale simulation have been used to both characterize the organization of the flow at lower levels at the foothills of the Pyrenees (where the experimental campaign was located), and to complement the observations.

It is found that TKE decreases along the AET and reaches a minimum close to sunset, in agreement to other studied days of the BLLAST dataset. However, for the present study, an LLJ develops over the area afterwards as a combination of large-scale winds and the mountain-plain circulation generated due to the vicinity of the Pyrenees. This major feature remains nearly stationary during the whole night and is responsible for the increment of the TKE close to the surface and at higher elevations above the wind speed maximum after sunset. In addition to its intensity, the turbulence isotropy has been analysed for the AET. During the day, a well-developed convective boundary layer is characterized by isotropic tur- bulence (anisotropy ratio of 1), whereas after sunset, vertical motions are damped due to the establishment of a stably stratified ABL and the wind shear generated by the LLJ. A comparison with a similar day of the BLLAST campaign without the occurrence of an LLJ confirms that the anisotropy ratio is enhanced due to its presence. The increment of anisotropy is less pronounced in the mesoscale simulation, probably due to the fact that the larger scales resolved by the model are less affected by thermal stratification and wind shear.

The use of unmanned aerial vehicles for measuring turbulence properties has experienced a large increase since the first reports of measuring the 3-D wind at high resolution on such systems (van den Kroonenberg et al., 2008). Information on turbulence properties is essential for many fields investigating atmospheric processes, e.g. the formation of new small particles (Platis et al., 2015), the dynamics of the morning transition (Wildmann et al., 2015), and applications in wind energy (Wildmann et al., 2014). The unmanned systems contribute valuable complementary information to other remote sensing and in situ measurement systems. Their limitations in horizontal and vertical operation range are balanced by the large flexibility of using the systems (no need for a runway, only small crew necessary for the operation). As was shown in this case study, the high-resolution measurements provide additional information at variable altitudes, which enables a large portfolio of applications in atmospheric research.

\section{Data availability}

Metadata and data from the BLLAST campaign are available after registration at: http://bllast.sedoo.fr/.

Acknowledgements. The authors would like to thank Andreas Scholtz, Thomas Krüger and Jürgen Heckmann for piloting the $\mathrm{M}^{2} \mathrm{AV}$ during the BLLAST campaign. The BLLAST field experiment was made possible thanks to the contribution of several institutions and supports: INSU-CNRS (Institut National des Sciences de l'Univers, Centre national de la Recherche Scientifique, LEFE-IDAO program), Météo-France, Observatoire Midi-Pyrénées (University of Toulouse), EUFAR (EUropean Facility for Airborne Research) and COST ES0802 (European Cooperation in the field of Scientific and Technical). The field experiment would not have occurred without the contribution of all participating European and American research groups, which all contributed a significant amount (see supports). BLLAST field experiment was hosted by the instrumented site of Centre de Recherches Atmosphériques, Lannemezan, France (Observatoire Midi-Pyrénées, Laboratoire d'Aérologie). The $60 \mathrm{~m}$ tower was partly supported by the POCTEFA/FLUXPYR European program. BLLAST data are managed by SEDOO, from Observatoire Midi-Pyrénées. The authors would like to thank Barbara Altstädter for critically proofreading the manuscript. The authors from Majorca acknowledge the support of the Spanish government and FEDER through the research project CGL2015-65627-C3-1-R. 
The French ANR (Agence Nationale de la Recherche) is supporting the analysis of the BLLAST dataset. Finally, the authors would like to thank three anonymous referees, who encouraged us to rewrite the manuscript completely, and Penny Rowe for proofreading the English.

Edited by: R. J. Beare

\section{References}

Acevedo, O. and Fitzjarrald, D. R.: The Early Evening SurfaceLayer Transition: Temporal and Spatial Variability, J. Atmos. Sci., 58, 2650-2667, 2001.

Baas, P., Bosveld, F. C., Klein Baltink, H., and Holtslag, A. A. M.: A Climatology of Nocturnal Low-Level Jets at Cabauw, J. Appl. Meteorol. Clim., 48, 1627-1642, doi:10.1175/2009JAMC1965.1, 2009.

Banta, R. M.: Stable-boundary-layer regimes from the perspective of the low-level jet, Acta Geophys., 56, 58-87, doi:10.2478/s11600-007-0049-8, 2008.

Banta, R. M., Pichugina, Y. L., and Newsom, R. K.: Relationship between low-level jet properties and turbulence kinetic energy in the nocturnal stable boundary layer, J. Atmos. Sci., 60, 25492555, 2003.

Banta, R. M., Pichugina, Y. L., and Brewer, W. A.: Turbulent velocity-variance profiles in the stable boundary layer generated by a nocturnal low-level jet, J. Atmos. Sci., 63, 2700-2719, 2006.

Beare, R. J., Edwards, J. M., and Lapworth, A. J.: Simulation of the observed evening transition and nocturnal boundary layers: Large-eddy simulation, Q. J. Roy. Meteor. Soc., 132, 81-99, 2006.

Blackadar, A. K.: Boundary layer wind maxima and their significance for the growth of nocturnal inversions, B. Am. Meteorol. Soc., 38, 283-290, 1957.

Bonner, W. D.: Climatology of the low level jet, Mon. Weather Rev., 96, 833-850, 1968.

Busse, J. and Knupp, K.: Observed Characteristics of the Afternoon-Evening Boundary Layer Transition Based on Sodar and Surface Data, J. Appl. Meteorol. Clim., 51, 571-582, 2012.

Canut, G., Couvreux, F., Lothon, M., Legain, D., Piguet, B., Lampert, A., and Moulin, E.: Turbulence measurements with a tethered balloon, Atmos. Meas. Tech. Discuss., doi:10.5194/amt2015-386, in review, 2016.

Caughey, S. J., Wyngaard, J. C., and Kaimal, J. C.: Turbulence in the evolving stable boundary layer, J. Atmos. Sci., 36, 1041-1052, 1979.

Conangla, L. and Cuxart, J.: On the turbulence in the upper part of the low-level jet: An experimental and numerical study, Bound.Lay. Meteorol., 118, 379-400, 2006.

Cuxart, J. and Jiménez, M. A.: Mixing Processes in a Nocturnal Low-Level Jet: An LES Study, J. Atmos. Sci, 64, 1666-1679, 2007.

Cuxart, J., Cunillera, J., Jiménez, M. A., Martínez, D., Molinos, F., and Palau, J. L.: Study of mesobeta basin flows by remote sensing, Bound.-Lay. Meteorol., 143, 143-158, 2012.

Cuxart, J., Wrenger, B., Martínez-Villagrasa, D., Reuder, J., Jonassen, M. O., Jiménez, M. A., Lothon, M., Lohou, F., Hartogensis, O., Dünnermann, J., Conangla, L., and Garai, A.: Estima- tion of the advection effects induced by surface heterogeneities in the surface energy budget, Atmos. Chem. Phys. Discuss., doi:10.5194/acp-2015-1051, in review, 2016.

Darbieu, C., Lohou, F., Lothon, M., Vilà-Guerau de Arellano, J., Couvreux, F., Durand, P., Pino, D., Patton, E. G., Nilsson, E., Blay-Carreras, E., and Gioli, B.: Turbulence vertical structure of the boundary layer during the afternoon transition, Atmos. Chem. Phys., 15, 10071-10086, doi:10.5194/acp-1510071-2015, 2015.

Emeis, S.: Wind speed and shear associated with low-level jets over Northern Germany, Meterol. Z., 23, 295-304, doi:10.1127/09412948/2014/0551, 2014.

Fitzjarrald, D. R. and Lala, G. G.: Hudson Valley Fog Environments, J. Appl. Meteorol., 28, 1303-1328, 1989.

Grant, A. L. M.: An observational study of the evening transition boundary-layer, Q. J. Roy. Meteor. Soc., 123, 657-677, 1997.

Gultepe, I., and Starr, D. O. C.: Dynamical Structure and Turbulence in Cirrus Clouds: Aircraft Observations during FIRE, J. Atmos. Sci., 52, 4159-4182, 1995.

Jiménez, M. A. and Cuxart, J.: A study of the nocturnal flows generated in the north side of the Pyrenees, Atmos. Res., 145146, 244254, doi:10.1016/j.atmosres.2014.04.010, 2014.

Jonassen, M. O., Tisler, P., Altstädter, B., Scholtz, A., Vihma, T., Lampert, A., König-Langlo, G., and Lüpkes, C.: Application of remotely piloted aircraft systems in observing the atmospheric boundary layer over Antarctic sea ice in winter, Polar Res., 34, 25651, doi:10.3402/polar.v34.25651, 2015.

Kallistratova, M. A., Kouznetsov, R. D., Kramar, V. F., and Kuznetsov, D. D.: Profiles of Wind Speed Variances within Nocturnal Low-Level Jets Observed with a Sodar, J. Atmos. Ocean. Tech., 30, 1970-1977, 2013.

Lafore, J. P., Stein, J., Asencio, N., Bougeault, P., Ducrocq, V., Duron, J., Fischer, C., Héreil, P., Mascart, P., Masson, V., Pinty, J. P., Redelsperger, J. L., Richard, E., and Vilà-Guerau de Arellano, J.: The Meso-NH Atmospheric Simulation System. Part I: adiabatic formulation and control simulations, Ann. Geophys., 16, 90-109, doi:10.1007/s00585-997-0090-6, 1998

Lampert, A., Bernalte Jimenez, B., Gross, G., Wulff, D., and Kenull, T.: One Year Observations of the Wind Distribution and LowLevel Jet Occurrence at Braunschweig, North German Plain, Wind Energy, doi:10.1002/we.1951, online first, 2015.

Legain, D., Bousquet, O., Douffet, T., Tzanos, D., Moulin, E., Barrie, J., and Renard, J.-B.: High-frequency boundary layer profiling with reusable radiosondes, Atmos. Meas. Tech., 6, 21952205, doi:10.5194/amt-6-2195-2013, 2013.

Lenschow, D. H., Li, X. S., Zhu, C. J., and Stankov, B. B.: The stably stratified boundary layer over the Great Plains. I. Mean and turbulence structure, Bound.-Lay. Meteorol., 42, 95-121, 1988.

Lenschow, D. H., Mann, J., and Kristensen, L: How Long is Long Enough When Measuring Fluxes and Other Turbulence Statistics?, J. Atmos. Ocean. Techn., 11, 661-673, 1994.

Lothon, M., Lohou, F., Pino, D., Couvreux, F., Pardyjak, E. R., Reuder, J., Vilà-Guerau de Arellano, J., Durand, P., Hartogensis, O., Legain, D., Augustin, P., Gioli, B., Lenschow, D. H., Faloona, I., Yagüe, C., Alexander, D. C., Angevine, W. M., Bargain, E., Barrié, J., Bazile, E., Bezombes, Y., Blay-Carreras, E., van de Boer, A., Boichard, J. L., Bourdon, A., Butet, A., Campistron, B., de Coster, O., Cuxart, J., Dabas, A., Darbieu, C., Deboudt, K., Delbarre, H., Derrien, S., Flament, P., Fourmentin, M., Garai, 
A., Gibert, F., Graf, A., Groebner, J., Guichard, F., Jiménez, M. A., Jonassen, M., van den Kroonenberg, A., Magliulo, V., Martin, S., Martinez, D., Mastrorillo, L., Moene, A. F., Molinos, F., Moulin, E., Pietersen, H. P., Piguet, B., Pique, E., RománCascón, C., Rufin-Soler, C., Saïd, F., Sastre-Marugán, M., Seity, Y., Steeneveld, G. J., Toscano, P., Traullé, O., Tzanos, D., Wacker, S., Wildmann, N., and Zaldei, A.: The BLLAST field experiment: Boundary-Layer Late Afternoon and Sunset Turbulence, Atmos. Chem. Phys., 14, 10931-10960, doi:10.5194/acp14-10931-2014, 2014.

Luhar, A. K.: Estimating Variances of Horizontal Wind Fluctuations in Stable Conditions, Bound.-Lay. Meteorol., 135, 301311,2010

Mahrt, L.: The early evening boundary layer transition, Q. J. Roy. Meteor. Soc., 107, 329-343, 1981.

Martin, S. and Bange, J.: The Influence of Aircraft Speed Variations on Sensible Heat-Flux Measurements by Different Airborne Systems, Bound.-Lay. Meteorol., 150, 153-166, 2014.

Martin, S., Bange, J., and Beyrich, F.: Meteorological profiling of the lower troposphere using the research UAV " $\mathrm{M}^{2} \mathrm{AV}$ Carolo", Atmos. Meas. Tech., 4, 705-716, doi:10.5194/amt-4-705-2011, 2011.

Martin, S., Beyrich, F., and Bange, J.: Observing Entrainment Processes Using a Small Unmanned Aerial Vehicle: A Feasibility Study, Bound.-Lay. Meteorol., 150, 449-467, doi:10.1007/s10546-013-9880-4, 2014.

Mason, P. J. and Thomson, D. J.: Large-Eddy simulations of the neutral-static-stability planetary boundary layer, Q. J. Roy. Meteor. Soc., 113, 413-443, 1987.

Mauritsen, T. and Svensson, G.: Observations of Stably Stratified Shear-Driven Atmospheric Turbulence at Low and High Richardson Numbers, J. Atmos. Sci., 64, 645-655, 2007.

Meischner, P., Baumann, R., Höller, H., and Jank, T.: Eddy Dissipation Rates in Thunderstorms Estimated by Doppler Radar in Relation to Aircraft In Situ Measurements, J. Atmos. Ocean. Technol., 18, 1609-1627, 2001.

Nadeau, D. F., Pardyjak, E. R., Higgins, C. W., Fernando, H. J. S., and Parlange, M. B.: A simple model for the afternoon and early evening decay of convective turbulence over different land surfaces, Bound.-Lay. Meteorol., 141, 301-324, 2011.

Nakanishi, M., Shibuya, R., Ito, J., and Niino, H.: Large-Eddy Simulation of a Residual Layer: Low-Level Jet, Convective Rolls, and Kelvin-Helmholtz Instability, J. Atmos. Sci., 71, 4473-4491, 2014

Paluch, I. R. and Baumgardner, D. G.: Entrainment and Fine-Scale Mixing in a Continental Convective Cloud, J. Atmos. Sci., 46, 261-278, 1989.
Platis, A., Altstädter, B., Wehner, B., Wildmann, N., Lampert, A., Hermann, M., Birmili, W., and Bange, J.: An Observational Case Study on the Influence of Atmospheric Boundary-Layer Dynamics on New Particle Formation, Bound.-Lay. Meteorol., 158, 6792, 2015.

Prabha, T. V., Leclerc, M. Y., Karipot, A., Hollinger, D. Y., and Mursch-Radlgruber, E.: Influence of Nocturnal Low-level Jets on Eddy-covariance Fluxes over a Tall Forest Canopy, Bound.-Lay. Meteorol., 126, 219-236, 2008.

Román-Cascón, C., Yagüe, C., Mahrt, L., Sastre, M., Steeneveld, G.-J., Pardyjak, E., van de Boer, A., and Hartogensis, O.: Interactions among drainage flows, gravity waves and turbulence: a BLLAST case study, Atmos. Chem. Phys., 15, 9031-9047, doi:10.5194/acp-15-9031-2015, 2015.

Song, J., Liao, K., Coulter, R. L., and Lesht, B. M.: Climatology of the low-level jet at the southern Great Plains Atmospheric Boundary Layer Experiment Site, J. Appl. Meteor., 44, 15931606, 2005.

Spiess, T., Bange, J., Buschmann, M., and Vörsmann, P.: First application of the meteorological Mini-UAV " $\mathrm{M}^{2} \mathrm{AV}$ ", Meteorol Z., 16, 159-169, 2007.

Stickney, T. M., Shedlov, M. W., and Thompson, D. I.: Goodrich Total Temperature Sensors, Technical Report, 5755, C, 32 pp., available at: http://www.faam.ac.uk/index.php/faam-documents/ science-instruments/47-rosemount-report-5755/file (last access: 28 June 2016), 1994.

Stull, R. B.: An Introduction to Boundary Layer Meteorology, Kluwer Academic Publishers, Reprint 1991, 666 pp., 1988.

Thebaud, L.: An atmospheric turbulent velocity spectrum for three dimensions, J. Geophys. Res., 109, D10109, doi:10.1029/2002JD003173, 2004.

van den Kroonenberg, A. C., Martin, T., Buschmann, M., Bange, J., and Vörsmann, P.: Measuring the Wind Vector Using the Autonomous Mini Aerial Vehicle $\mathrm{M}^{2} \mathrm{AV}$, J. Atmos. Ocean. Tech., 25, 1969-1982, 2008.

van den Kroonenberg, A., Martin, S., Beyrich, F., and Bange, J.: Spatially-Averaged Temperature Structure Parameter Over a Heterogeneous Surface Measured by an Unmanned Aerial Vehicle, Bound.-Lay. Meteorol., 142, 55-77, 2012.

Wildmann, N., Hofsäß, M., Weimer, F., Joos, A., and Bange, J.: MASC - a small Remotely Piloted Aircraft (RPA) for wind energy research, Adv. Sci. Res., 11, 55-61, doi:10.5194/asr-11-552014, 2014.

Wildmann, N., Rau, G. A., and Bange, J.: Observations of the Early Morning Boundary-Layer Transition with Small RemotelyPiloted Aircraft, Boundary-Lay. Meteorol., 157, 345-373, 2015. 